\title{
A Solution to Tough Logging Conditions (Lwf): Intro to Tough Logging Conditions, Logging While Fishing, Operation Procedure and Conditions
}

\author{
G. Bob Williams* \\ Department of Petroleum Engineering, UIE Chandigarh University, Mohali, Punjab, India \\ Email: ops0121@gmail.com

\section{Purabi Bora} \\ Department of Petroleum Engineering, UIE Chandigarh University, Mohali, Punjab, India \\ Omprakash Sahu \\ Department of Chemical Engineering, UIE Chandigarh University Mohali Punjab, India
}

\begin{abstract}
This review work summarised new generation logging techniques such Tough Logging Conditions (TLC) \& Logging While Fishing (LWF) and their advancement in drilling operations. The production of Oil \& gas from the stage of exploration to production should need a lot of data for economic and safe operations. The conditions of the sub-surface cannot be simply predicted unless with some measured parameters under the LOGGING term. Logging is defined as a continuous record of Petro's physical parameters of rock against time and depth. Instead of conventional logging techniques of wireline such as SP, Gamma-ray, Neutron, Calliper log, etc, logging while drilling, logging while fishing set them aside of their extended applications. Logging while Fishing is a new generation technology that allows unfailing operations of logging tool by a special installation even in cut and thread operation also aids economic and time enhancement. Tough logging conditions are a technique applied either when the hole has highly deviated or when you need to control the position of a tool. This project includes the study and interpretation of above discussed new generation logs. These tools offer all types of logging carried out on wireline except the SP logging. Logging while drilling provides real-time measurements of physical parameters while drilling operation itself which avoids an additional running of tools causing trips and sticking of drill pipe. The data is stored in the bottom assembled logging tool.
\end{abstract}

Keywords: Wireline logging; Tough logging conditions; Drilling; Well intervention; Fishing; Drill pipe stuck.

\section{Introduction}

In the oil and gas industry, exploration is always a hit-and-miss method despite many new technologies it's still gambling. With primary geological and geophysical examinations such as from interpretation of contour maps, physical measurements such as seismic, gravity, magnetic, etc, from which the area of interest can be determined. For safe and economic drilling, well planning is provided with a GTO having.

i. $\quad$ General data

ii. Geological data

iii. Geophysical data

iv. Drilling data

v. Mud data

This GTO provides all particulars regarding bit selection, casing selection, casing shoe depth, lithology, etc. All this data is the estimation in real-time while drilling the well always offers challenging conditions. The conditions encountered in sub-surface are apart from the data available in GTO so sub-surface conditions must measure for a safe operation. This can be termed as "formation evaluation". Formation evaluation is nothing but evaluation of all the potential reservoirs encountered after exploratory drilling for hydrocarbon potential.

Important parameters that are evaluated are.

1. Depth of the reservoir

2. Thickness

3. Porosity

4. Permeability

5. Formation water salinity

6. Hydrocarbon Saturation

7. Moveable hydrocarbon

8. Hydrocarbon reserve estimates

9. Depositional environments

10. True dip of the formation

The tools used for evaluation: 
1. Borehole logging. All logs like SP, resistivity (deep and shallow), radioactivity logs like neutron, gammaray, acoustic, density, caliper, dip meter, etc.

2. Conventional cores, sidewall cores.

3. Wireline samplers like SFT, RFT, and MDT.

To understand the advantages of logging while fishing one must understand the basics of conventional logging techniques. In general logging operations are done by wireline mounted to a truck and this process or operation is called wireline logging.

\subsection{Wire-Line Logging}

The word LOG refers to a particular curve, a suit or group of curves, representing the variation of a physical parameter with depth. Wire-line logging or Geophysical logging or Electro logging is the practice of making a detailed record (a well log) of geophysical measurements of the geologic formations penetrated by a borehole using various instruments housed in a tool (sonde) conveyed to the bottom by a wire-line. These can be recorded in either open holes or cased holes. Broadly these tools can be divided into lithological (Gamma, SP, and Resistivity), porosity (Sonic, Neutron, and Density), and special logs (MDT, CBL-VDL, FMI, Dip meter, etc). Electro logs give vital information on hydrocarbon-bearing zones, lithologies, thickness \& depth of potential reservoirs, formation boundaries, geological correlations, etc.

\subsection{Gamma Ray Logging Tool}

Before getting into how to use the log readings, let us consider the workings of the tool. Unlike all other nuclear tools (and, in fact, all other logging measurements), it is completely passive. It emits no radiation. Instead, it simply detects incoming gamma rays from the formation and (unfortunately) the borehole. Gamma rays are electromagnetic radiation, generally in the energy range of 0.1 to $100 \mathrm{MeV}$. As light, this would correspond to very short wavelengths indeed. The difference between gamma rays and X-rays is largely semantic because they overlap in energy.

Originally, the detector was a Geiger-Mueller tube, just as in the Geiger counter. More recently, the detectors have been switched to solid-state scintillation crystals such as NaI. When a gamma-ray strikes such a crystal, it may be absorbed. If it is, the crystal produces a flash of light. This light is "seen" by a photomultiplier staring into the end of the crystal. The photomultiplier shapes the light into an electrical pulse that is counted by the tool. Hence, like all nuclear tools, the raw measured quantity in a gamma-ray log is counted. This means that the precision of gamma-ray $\log$ measurements is determined by Poisson statistics. The precision is the square root of the total number of counts recorded at a given depth. Counts recorded are proportional to the volume of the detector crystal times its density (which determines the probability that a gamma-ray will be captured within the crystal) times the length of time counted. As with all nuclear-logging measurements, the only part of this that the logger controls is the counting time. Because log measurements are depth-driven, the length of time the logger counts is inversely proportional to the logging speed.

Historically, gamma-ray sondes have recorded the total flux of gamma radiation integrated overall energies emanating from a formation as a single count rate, the gamma-ray curve. Logging tools are not uniform in their energy sensitivity. No detector responds to all the gamma rays that impinge on it. Many pass through with no effect. The sizes of a detector, the solid angle it subtends, and its thickness, as well as its composition (particularly its density), all affect its efficiency for detecting gamma rays. The tool housing around the detector, the casing, and even the density of the borehole fluid can all filter the gamma rays coming from the formation. All these factors not only lower the overall tool efficiency but also lead to variations in efficiency for gamma rays of different energies. In short, the count rate recorded in a particular radioactive shale bed is not a unique property of the shale. It is a complex function of tool design and borehole conditions as well as the actual formation's radioactivity.

\subsection{Spectral Logging}

It is a specialized gamma radiation logging to distinguish the three-component decay chains (potassium, uranium, and thorium) by the wavelengths of their characteristic gamma emissions. The characteristic gamma-ray line that is associated with each component:

- Potassium: Gamma-ray energy $1.46 \mathrm{MeV}$

- Thorium series: Gamma-ray energy $2.62 \mathrm{MeV}$

- Uranium-Radium series: Gamma-ray energy $1.76 \mathrm{MeV}$

\subsection{Spontaneous Potential Log (Self-Potential Log or Sp Log) Principle}

It works by measuring the electric potential difference (measured in mill volts) between the electrode at the bottom of the borehole and a grounded electrode at the surface. It is generally run along with the gamma-ray. Clays and shales will generate one charge and permeable formations such as sandstone will generate an opposite one. This build-up of charge is, in turn, caused by differences in the salt content of the wellbore fluid (drilling mud) and the formation water (connate water). The potential opposite shales are called the baseline and typically shift only slowly over the depth of the borehole. The salt content of the connate water will determine the SP curve to deflect either +ve or -ve against a permeable formation.

If the salinity of the mud is similar to the formation water then the SP curve may give little or no response opposite a permeable formation; if the mud is more saline, then the curve has a positive voltage concerning the baseline opposite permeable formations; if it is less, the voltage deflection is negative. Mud invasion into the 
permeable formation can cause the deflections in the SP curve to be rounded off and to reduce the amplitude of thin beds. SP data can be used to locate the permeable formations; the boundaries of these formations; and to determine the values for the formation-water resistivities.

\subsection{Caliper Log}

It is a set of measurements of the size and shape of a borehole commonly made when drilling oil and gas wells. This can be an important indicator of cavings or shale swelling in the borehole $\&$ the presence of the mud cake. It is constructed with two or more articulated arms that push against the borehole wall to take measurements. The caliper $\log$ is printed as a continuous series of values of hole diameter with depth against the drilled bit size. Open hole calipers comprise up to six arms attached to the body of a sonde and held against the borehole wall by spring action. They provide a continuous measurement of borehole diameter. In general, one- and two-arm calipers measure only the maximum diameter where a hole is not circular. Four- and six-arm tools define the hole size and shape, and this is especially important in deviated wells and elliptically shaped wellbores. However, the size and pressure of the contacting arms also affect the measured data. This means that a caliper run with the density-log tool string might show a larger hole diameter than one run with the induction log. This is because the density tool is a pad device, and the pad cuts through the mud cake to sense a larger diameter, whereas the induction tool is a mandrel device (i.e., it is essentially contained within a cylindrical housing). For these reasons, different open hole caliper logs should not be expected to show precise repeatability.

The movement of the caliper arms must be converted to something measurable at the surface. Most modern calipers use a potentiometer circuit connected to the caliper arms using transducers. The circuitry can use direct current or pulses. In the former case, the displacement of the arms translates directly to a voltage within the measuring circuit. Pulsed caliper tools use the potentiometer to deliver a variable voltage to a voltage-frequency circuit. The frequency of the pulse train is proportional to the extension of the caliper arm. A basic problem with armed calipers is that the extension of an arm is not directly proportional to the displacement of the transducer. This gives rise to a nonlinear response, which is linearized through data processing based on detailed calibration data. A caliper tool is designed to operate over a specified range of hole diameter. The design sets out to minimize the nonlinearity of tool response over this range.

\subsection{Resistivity Log}

It is a method of well logging that works by characterizing the rock or sediment in a borehole by measuring its electrical resistivity by sending current into formation. Resistivity is the ability to impede the flow of current through rock and is expressed as ohm-meter/meter or ohm. Resistivity logs are either laterolog or Induction type. The laterolog tools use electrodes to inject a current into the formation and to measure voltages at different points in the tool. The induction tools use coils and magnetic fields to develop currents in the formation whose intensity is proportional to the conductivity of the formation. The intensity of these currents is measured on receiver coils in the tool. Most rock materials are essentially insulators, while their enclosed fluids (saline water) are conductors. Hydrocarbon fluids are an exception because they are almost infinitely resistive. High resistivity values may indicate a hydrocarbon-bearing formation. Resistivity logging is a method of well logging that works by characterizing the rock or sediment in a borehole by measuring its electrical resistivity. Resistivity is a fundamental material property that represents how strongly a material opposes the flow of electric current. In these logs, resistivity is measured using 4 electrical probes to eliminate the resistance of the contact leads. The log must run in holes containing electrically conductive mud or water. Resistivity logging is sometimes used in mineral exploration (especially exploration for iron and potassium) and water-well drilling, but most commonly for formation evaluation in oil- and gas-well drilling. Most rock materials are essentially insulators, while their enclosed fluids are conductors. Hydrocarbon fluids are an exception because they are almost infinitely resistive. When a formation is porous and contains salty water, the overall resistivity will be low. When the formation contains hydrocarbon or contains very low porosity, its resistivity will be high. High resistivity values may indicate a hydrocarbon-bearing formation.

Usually, while drilling, drilling fluids invade the formation, changes in the resistivity are measured by the tool in the invaded zone. For this reason, several resistivity tools with different investigation lengths are used to measure the formation resistivity. If water-based mud is used and oil is displaced, "deeper" resistivity logs (or those of the "virgin zone") will show lower conductivity than the invaded zone. If oil-based mud is used and water is displaced, deeper logs will show higher conductivity than the invaded zone. This provides not only an indication of the fluids present but also, at least qualitatively, whether the formation is permeable or not.

\subsection{Sonic Log}

It shows a formation's interval transit time, designated as $\boldsymbol{d t}$. It is a measure of a formation's capacity to transmit sound (compressional) waves and is expressed in microseconds per foot. Geologically, this capacity varies with lithology and rock textures, notably porosity. The sonic tool is only capable of measuring travel time. It is proportional to the compaction trend of sediment with depth. Quantitatively, the sonic log is used to evaluate porosity in liquid-filled pores.

\subsection{Density Log}

It determines rock bulk density along a wellbore. This is the overall density of rock including solid matrix and the fluid enclosed in pores. A radioactive source in the tool continuously emits medium-energy gamma rays, which collide with electrons in the nuclei of the formation. With each collision, gamma rays lose some energy due to 


\section{Sumerianz Journal of Scientific Research}

Compton scattering and reach the detector, which in turn counts them with sufficient energy levels. The no. of Compton scattering collisions is related directly to the no. of electrons present in the formation, and hence the bulk density of the formation (no. of electrons per cubic $\mathrm{cm}$ of the formation). Geologically, bulk density is a function of the density of the minerals forming a rock (i.e. matrix) and the enclosed volume of free fluids (porosity).

\subsection{Neutron Log}

It employs a neutron source to measure the hydrogen index in a reservoir, which is directly related to porosity. The Hydrogen Index (HI) of a material is defined as the ratio of the concentration of hydrogen atoms per $\mathrm{cm}^{3}$ in the material, to that of pure water at $75^{\circ} \mathrm{F}$. The source mounted in Sonde emits high-energy neutrons, which collide with formation nuclei. With each collision, neutrons lose energy and are scattered, while some are captured by other nuclei like Hydrogen. The energy loss is greater when the collision takes place with a nucleus of equal mass such as Hydrogen.

The slowed-down scattered neutrons are detected by the detector in the Sonde. As hydrogen atoms are present in both water and oil-filled reservoirs, measurement of the amount allows estimation of the amount of liquid-filled porosity. A cross-over between Density and Neutron (plotted in reverse scale) reading in an LDL-CNL Log indicates the presence of possible hydrocarbons in the formation.

\subsection{Cement Bond Log}

Acoustic logging is used for the determination of cement bonds in cased wells. This type of log is most often referred to as a Cement Bond Log $(\mathrm{CBL})$. Acoustic signals propagated in steel casing are observed to have large amplitude in free (un-cemented) casing. The reason is that much of the energy is retained in the casing. The opposite effect is found in a casing that is in contact with a solid such as cement. The casing signal is much smaller in cemented casing because the energy is coupled into the surrounding cement and formation.

Drilling high angle or drilling to multiple targets increase the well productivity greatly [1]. For such critical conditions, conventional intervention tools available may not come into use. As the common word from a wireline engineer "I can't push the rope" when the tool is unable to reach the target depth due to the directed trajectories having high angles [2]. So, to overcome this many service companies came up with innovations to evaluate and access these complicated wellbores. Logging for the vertical wells was a quite easy task compared to the horizontal or directed wells. The tool was set to target dept by the gravity and while retrieving data was recorded [3]. Communication with the tool is achieved by the cable to supply power and retrieve the data. But today, gravity is not the only means of getting tools to the bottom of the well, and cables are not the only mean of delivering data to the surface; tool delivery, data transmission, and equipment methods abound. With today's technology, drilling engineers can create such complex wellbore geometries that delivering downhole tools to a targeted formation becomes a challenge. These wells require evaluation information when they are drilled, and they will also require some means to access the reservoir for future evaluation and intervention [4]. Conveyance consists of more than the mechanisms of pulling and pushing tools down the hole. Its greater purpose is to address the challenges created by wellbore environments. These challenges Include deploying tools at the surface, overcoming frictional forces, maneuvering past obstacles, and adapting to unforeseen downhole conditions [5]. Conveyance methods can be grouped into two basic types: cable conveyed and pipe conveyed. Within both categories are variations and hybrid solutions that blend elements of the other. The various methods come with trade-offs, strengths, and weaknesses, so there is rarely a perfect solution. Cable-conveyed tools have a long history. The first electric log, acquired at Pechelbronn fields in Alsace, France, on September 5, 1927, was run on a cable. The survey instrument was lowered $300 \mathrm{~m}[980 \mathrm{ft}]$ into the well, and subsurface measurements were plotted by hand as the tool was slowly retrieved using a manually operated winch. Surface units used for acquisition have also become more and more sophisticated. But the well logging landscape experienced its most dramatic transformation in the 1980s with the introductions of logging-while-drilling (LWD) tools. LWD tools are an integral part of the drill string bottom hole assembly (BHA) [6]. In the early days, measurements were fairly basic; they included gamma-ray and resistivity, followed by the addition of porosity measurements [7]. The tools communicate via a series of pressure pulses transmitted through the circulating drilling mud to convey commands downhole and deliver data to the surface. These pressure pulses age encoded with data about well conditions, the status of the BHA, and the formations encountered by the bit. Mud pulse telemetry transmits data at rates that are several orders of magnitude lower than those achieved using logging cables; but, given the time required for drilling operations, this method has generally proved to be sufficient. Other transmission methods are available; for example, electromagnetic telemetry in air or foam drilling. In addition to that more recently, a wired drill pipe, which can send data using an embedded transmission cable, has been introduced. Wired drill pipe promises high data rates: 57,000 bites per second compared with 10 bits per second with mud pulse telemetry. Commercial transmission systems, such as the intelliserv broadband network, are currently available, although this technology has yet to replace mud pulse telemetry is the method of choice for service companies and operators. Using real-time information provided by LWD tools, directional drillers can remotely steer and guide the bit to specific targets, making precise corrections in wellbore trajectory [8]. As well trajectories shifted from vertical to horizontal, LWD data, in many cases, supplanted traditional wireline logging for formation evaluation. Meanwhile, the quality and scope of LWD data have improved, and sophisticated tool offerings are now available while drilling. For instance, the echoscope multifunction LWD service offers the echoscope multifunction LWD service offers resistivity, porosity, azimuthal density, ultrasonic caliper, capture spectroscopy, and azimuthal gamma-ray measurements in one compact tool [9]. Instead of a chemical radioactive source for neutrons, the tool uses a pulsed neutron generator powered by a turbine, which is driven by circulating mud. The tool also includes a 
variety of sensors that provide information to improve drilling operations. Logging companies can perform advanced services such as seismic, acoustic, and magnetic resonance logging while drilling. Pressure measurements and sampling, which have long been exclusively in the wireline logging domain, can now be carried out with LWD tools as well. Although the gap between wireline and LWD offerings continues to narrow, some services are not available while drilling. These include high-data-rate services, such as the FMI formation micro imager coring tool, tools requiring high power, such as sidewall coring tools, and other technologies that have yet to migrate to LWD platforms [10]. Eventually, the rig moves on to drill the next well, and LWD tools can no longer be used for data transmission. Even if they were available, LWD tools were not developed to perform cased hole services. Wireline tools are needed to evaluate and access the reservoir, although getting them to the bottom of horizontal and highangle wells is problematic. Thus, alternative means of conveyance have been developed to deliver these tools. Drillers can negotiate high-angle and difficult wellbores because drill pipe is stiff and heavy [11].

This is not the case with tools at the end of a wireline. In the past, when TD could not be reached with logging tools because of well conditions, engineers developed and attempted various methods to get past obstructions [12]. Operations have welded chains to the bottom of tools hoping that the chains would pile up on a ledge and eventually fall off and pull the tool down the hole. Weight bars, friction-reducing wheels, and rollers have been developed to facilitate tool movement. Schlumberger engineers even designed an articulated bottom nose that could be manipulated from the surface to locate the wellbore path when the tools stopped on ledges or where the hole exhibited a large washout. These attempts to overcome geometry and borehole irregularities are typically met with limited success. However, before the widespread acceptance of LWD tools, methods existed for conveying conventional open-hole logging tools at the end of the drill pipe. Among them was the TLC tough logging conditions system [10]. Logging tools, minus the cable, were attached to the end of the drill pipe and pushed to the bottom of the casing. Next, a specially designed connector, attached to the logging cable, was pumped down through the inside of the pipe. A wet-connect device latched onto the downhole tool string to provide power and communication to the tools. The drill pipe then pushed the tools. The drill pipe then pushed the tools into the open hole and onto the bottom of the well. A modified technique, logging while fishing (LWF), uses a concept similar to the TLC system. Should a conventional wireline logging tool become stuck in the well while logging, a cut-and-thread fishing operation is performed to engage the stuck tool with a grapple attached to the end of the drill pipe [11]. The severed cable is reconnected to the downhole tools, and then data are acquired as the pipe and tools are pulled out. This operation has been performed when crucial data were need but hole conditions made logging impossible. Both TLC and LWF methods are still in use today, offering the capability to acquire information that would otherwise be unobtainable. However, the process of running in the hole and logging can be slow. Perhaps more significant, the operator has little control over the tool at the end of the drill pipe during TLC operations. Drillers must also take precautions to avoid damaging the exposed logging cable and the tools while running them in the hole. Compared with the drill pipe and BHAs, the relatively fragile logging tools can be easily crushed or damaged. Engineers have designed specialized hardware and protective equipment as accessories to protect the tools, but a risk associated with pushing exposed tools, but the risk associated with pushing exposed tools through open holes remains [13]. Even with protections hardware, open-hole logging tools may encounter ledges, bridged sections of open holes, and large wash-out wellbore, making it impossible to push the tools to the bottom. Drillers often attempt pipe rotation to get around obstructions, which is not an option when tools are attached with operations. Recent use of the TLC concept has been developed that uses drill pipes to convey logging tools. The main differences are that the tools are protected inside a carrier while they are being run in the hole and no logging cable is required [12]. Once the drill string reaches the logging depth, the field engineer uses an injection mechanism to deploy battery-powered tools. Extended beneath the bottom of the drill pipe, these tools acquire the downhole data, which are stored in memory while the drill pipe is being pulled out of the hole. Pipe movement is recorded versus time during retrieval. At the surface, the time-based data from the downhole are recovered using a laptop computer and then merged with the depth data from the downhole are recovered using a computer and then merged with the depth data from pipe movement to generate conventional depth logs [14] s. A logging truck is not required. Because they are deployed inside drill pipes, the tools must have a smaller diameter than conventional logging equipment. The recently introduced multi express slim, multi conveyance formation evaluation platform is an example of a set of tools that can be deployed using the protective drill pipe carrier. With $[5.7-\mathrm{cm}]$ diameter, these tools fit inside the $[12.7 \mathrm{~cm}]$ OD carrier with enough clearance to circulate mud down the hole. The ability to circulate is an important feature for running drill pipe into the well, especially in long horizontal open hole sections in which cuttings can accumulate [9]. The multi-express platform includes induction, litho-density, thermal and epithermal neutron porosity, and array acoustic tools. The induction tool acquires data at two depths of Investigation deep and medium resistivity data [15]. The density tool has an articulated pad and caliper to provide good borehole contact. The compact telemetry neutron gamma-ray section can acquire both thermal and epithermal neutron porosity data. It includes a casing collar locator for depth correlation, which can be used with cement bond logging. The sonic data or in cased hole mode for cement bond logging. While developing this tool platform, engineers focused on minimizing tool length and weight. A triple combo tool string induction, density, and neutron tools consist of three devices of approximately $3 \mathrm{~m}$ [10ft] each and $9.75 \mathrm{~m}$ long when fully assembled. The $4.3-\mathrm{m}$ sonic tool can be included as well. The multi express family of tools was designed to be handled by one person; the heaviest tool weighs $40.8 \mathrm{~kg}$ the multi express tools are ideal for logging small wellbores, shallow wells, and air-filled holes. The platform includes the tools mentioned above plus an audio temperature tool, which supplies important measurements in coal bed methane and shallow air-drilled tight gas wells. These types of wells can be difficult to evaluate with conventional logging units because the wells have small drilling pads and the rigs move quickly from well site to well site. Logging engineers can access wells for both openhole logging and cement bond logging using fit-for-purpose logging trucks with integrated masts, such as the blue 
streak high-efficiency unit. Drilling and workover rigs are not required when engineers use these small, selfcontained logging units. Mooncalves logging cables with a single conductor are generally used instead of multiconductor cables that are common with conventional logging tool systems. With the memory recovery option, the multi-express tools can also be run with cables that have no conductor. This adds the capability of using slick line units for open-hole logging, although there is no surface readout using this method. Data acquisition and quality are confirmed after the tools have returned to the surface and the stored information is retrieved.

Fig-1. Tough Logging Conditions System

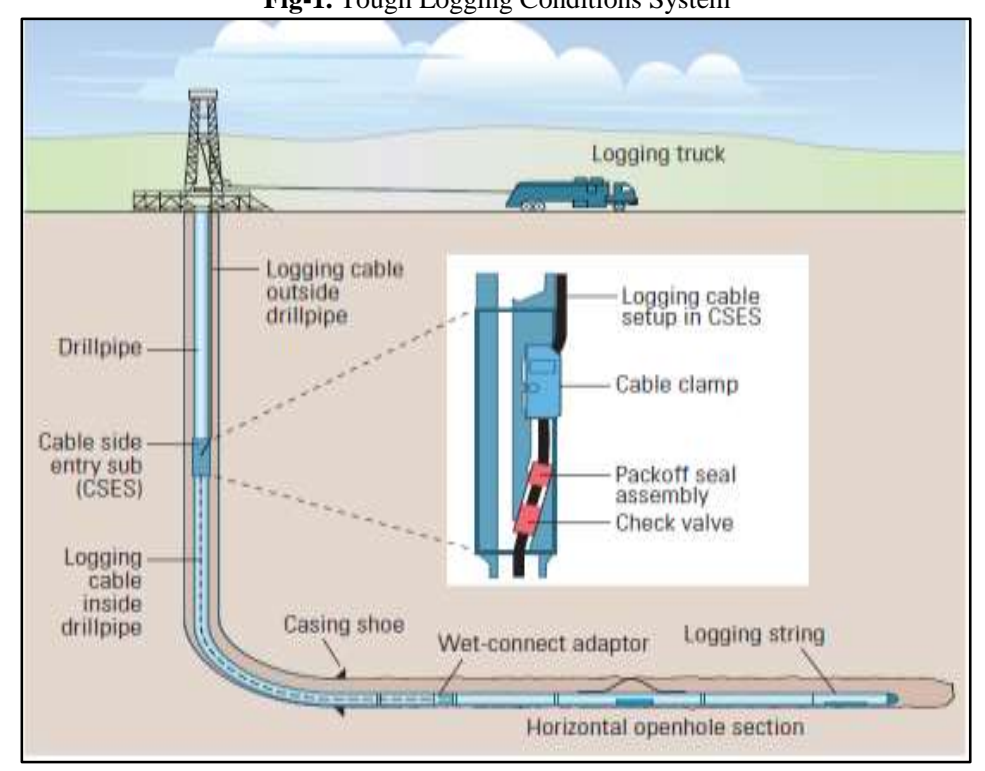

\section{Logging While Fishing}

Logging While Fishing is a method that combines drill pipe conveyed logging with cut and threads fishing LWF provides means for retrieving a stuck wireline logging tool and completing the logging run during the same pipe descent.

This new generation logging operation is widely carried out by specially designed tools.

The major purpose of the fishing operation is to retrieve the stuck pipe in the borehole. The factors causing this problem are:

i. The depositions of sand or heavy mud in the annulus cause pipe sticking.

ii. During the drilling and tripping operations, the string makes a grove on the heavy side called a "Key Seat".

iii. When the hydrostatic pressure due to fluid column is greater than the pressure offered by formation pores it increases the mud filtrate cake thickness causing "Differential Sticking".

iv. There are other numerous causes for stuck of pipe in a wellbore.

To retrieve the pipe back free point and the stuck point must determine. This is done by a special tool called Electro stat free point tool run on wireline. This tool is run in the pipe whose diameter is less compared to the pipe. The tool works on either applied stress or torque in the string at desired depths. The measurements are recorded by sensors which are transmitted to the control room by a wireline.

The "STREECTOR" tool is so sensitive to stress and measures even minute changes in the stress. This tool helps in measuring tension, compression, right and left torque. The tool is set into the string and the stress differences are measured between two desired points to determine free point and stuck point.

The "STREECTOR-II" was designed to run with coil tubing, slim holes with a diameter less than 5 inches which is operable at pressures more than $2000 \mathrm{psi}$ and temperatures of $400^{\circ} \mathrm{F}$. This tool is also aided to carry an explosion slot to cut the pipe. The back-off operation is done by the left-hand torque principle above the thread without damaging the thread.

\section{Operation}

i. The cable side entry sub (CSES) should never go into an open hole. The probability of cable damage is greatly increased when a CSES is run into an open hole.

ii. If a casing depth of $4000 \mathrm{ft}$, a maximum of $4000 \mathrm{ft}$ open hole can be logged by LWF.

iii. For most of the wells, the Cable side entry sub (CSES) and Cable Cutter Sub (CCTS) are installed when the tool overshoot is inside the casing near the shoe.

iv. The process of installing CSES/CCTS and converting from cut-thread to LWF takes about 30 minutes and during this time it may not be possible to move the drill pipe.

v. During the cut-thread phase of the job, $1000 \mathrm{lbs}$ over normal cable weight is maintained on the wireline as the drill pipe is threaded into the hole. When holding this tension, the wireline overshot \& weight assembly will be about $15-30$ feet above the drill floor.

vi. Rigs with top drives it is necessary to keep wireline overshot\& weight assembly below the top drives as drill pipe is threaded into the hole.

vii. This is best accomplished by running a "double" while holding $1000 \mathrm{lbs}$ over normal cable weight. 
viii. Logging tools have compressive load limits ranging from $23000 \mathrm{lbs}$ to $1500 \mathrm{lbs}$.

ix. If an ACTS or AMS exists in the logging tool string the logging engineer can accurately monitor tool compression in the logging unit, and radio this information to the drill floor as the tool is being engaged by the overshot or as the logging are being pushed down the hole.

x. Good communication is essential for safe and efficient LWF operations. The LWF specialist on location will conduct a pre-job meeting to cover safety issues and explain the LWF procedure to all persons involved in the job.

Fig-2.

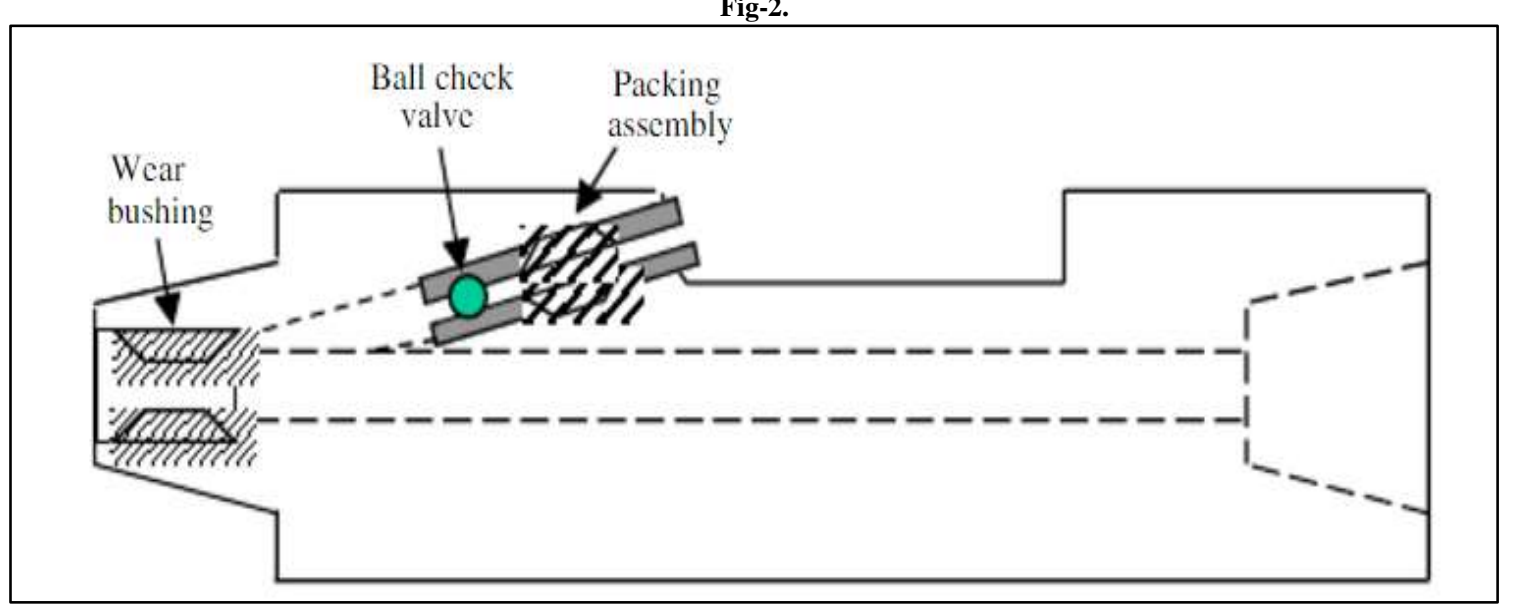

There are three cases of open access from Schlumberger case studies where LWF technology is used in the Gulf of Mexico to illustrate rig time and cost-effectively saved in fishing operation.

CASE1

1. LWF service is used to recover MDT (Modular Formation Dynamic Tester Tool).

2. Well drilled to a depth of 11,000 with upper deviated up to 35 .

3. The pressure test revealed that the well was considerably overbalanced, $80 \mathrm{ft}$ long tool got stuck at depth of $10,200 \mathrm{ft}$.

4. Using the LWF tool to capture the tool and also allowed to continue fluid and pressure sampling below $100 \mathrm{ft}$ from the stuck point.

\section{CASE 2}

1. LWF service is used to recover MDT (Modular Formation Dynamic Tester Tool).

2. It is an exploratory well drilled to a depth of 16,350 feet.

3. There is no evidence of sticking cause of the straight hole and no over-pull.

4. But 113 feet the long MDT tool got stuck at depth of 14,620 feet.

5. The LWF technique was able to re-establish the logging operations within $17 \mathrm{hrs}$, and the drill pipe conveyed tool recovered additional fluid and pressure sampling for $13 \mathrm{hrs}$.

\section{CASE 3}

1. To recover triple - combo tool.

2. The well was drilled to a depth of 9,200 with a deviation of 27 , and $103 / 4$ casing set to $2000 \mathrm{ft}$.

3. $82 \mathrm{ft}$ long triple-combo tool got stuck at $8,900 \mathrm{ft}$.

4. Once the tool was engaged using LWF technology, it was lowered by one standpipe to obtain the data required for a continuous log from total depth to $2000 \mathrm{ft}$ where the tool become stuck.

\subsection{LWF Time and Cost Savings for Case Studies}

\begin{tabular}{l|l|l|l}
\hline Time, hr & Conventional Fishing & LWF method & Total Savings \\
\hline Case 1 & 50 & 31 & 19 \\
\hline Case 2 & 87 & 48 & 39 \\
\hline Case 3 & 55 & 27 & 28 \\
\hline \multicolumn{4}{|l}{} \\
\hline Cost, USD & Conventional Fishing & LWF method & Total Savings \\
\hline Case 1 & $1,00,000$ & 61,000 & 39,000 \\
\hline Case 2 & $2,17,500$ & $1,20,000$ & 97,500 \\
\hline Case 3 & $1,09,500$ & 53,000 & 56,500 \\
\hline
\end{tabular}




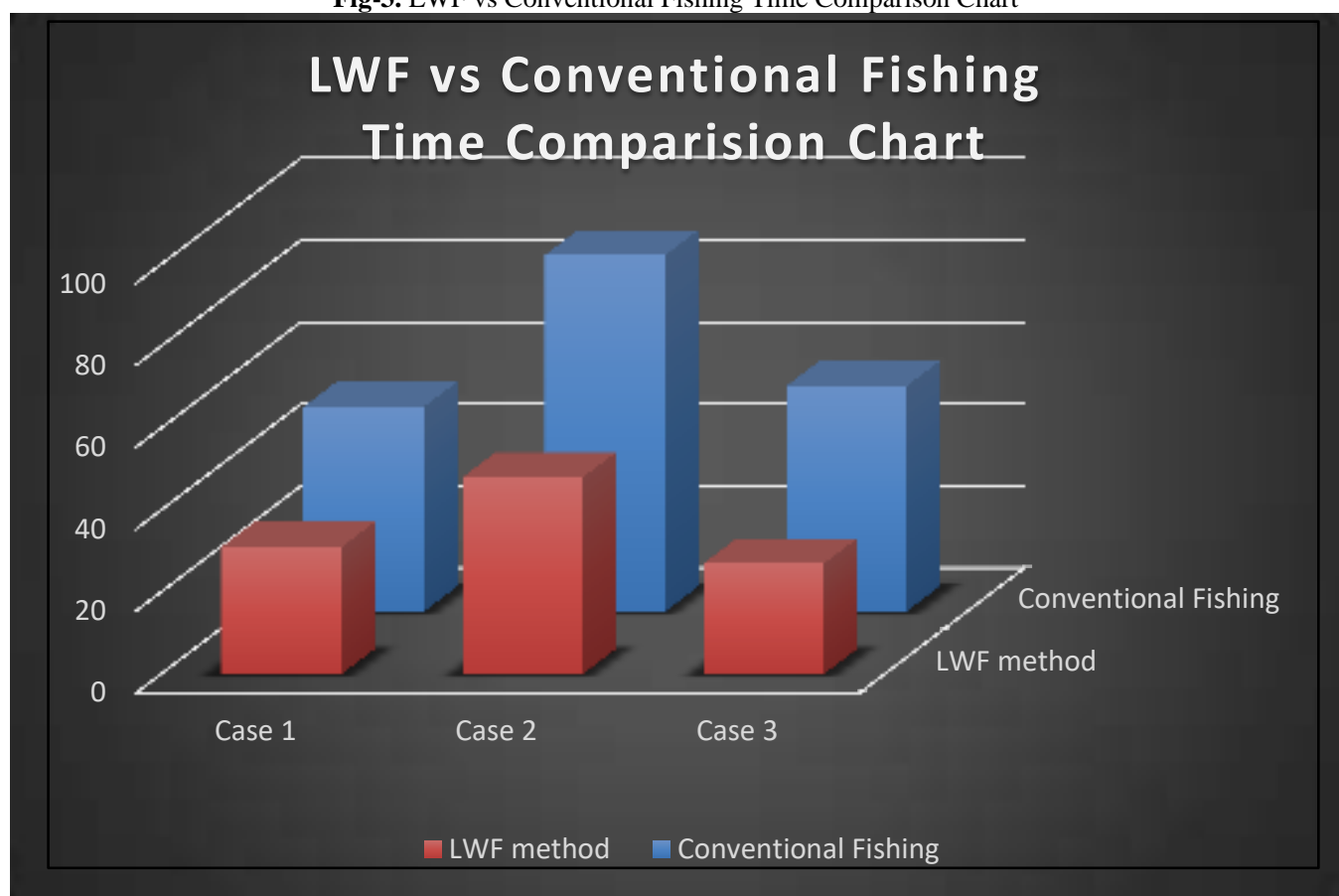

Fig-4. LWF vs Conventional Logging Cost Comparison Chart

\section{LWF vs Conventional Logging Cost Comparison Chart}

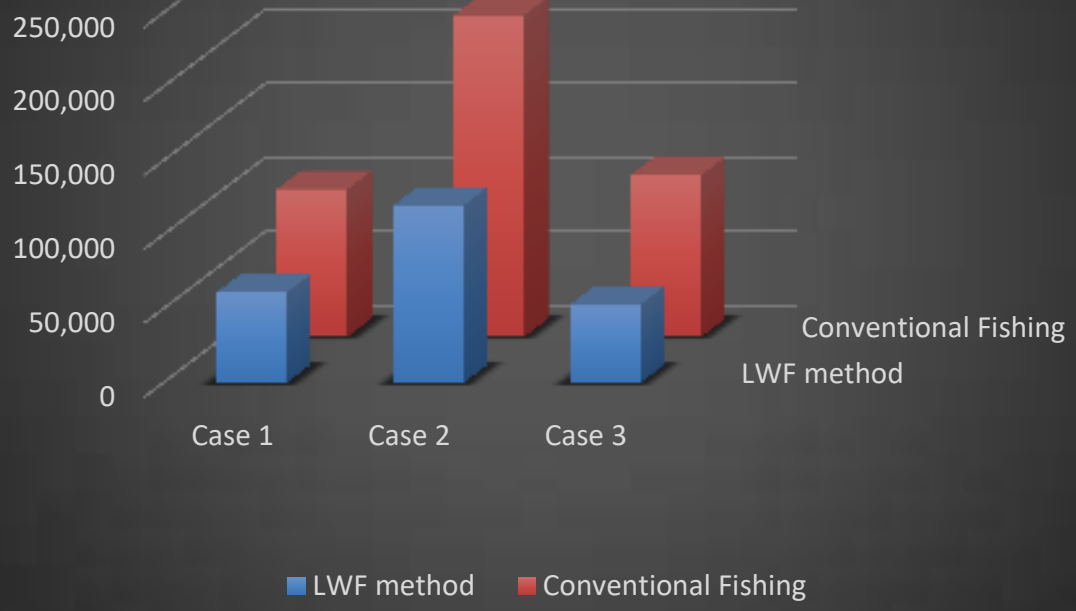

\section{Conclusion}

The present technology is still having holds in certain cases so the development of new technology is needed to extend the application. The invention of LWD has contributed on a large scale to overcome the limitation of wireline logging such as differential sticking, limitation in deviated wells, and the tool needs trip. These limitations laid a path for LWD provided with real-time data by the MWD method and no trip required. Either the data can be stored in a down storage disk or monitored in real-time by the mud pulse telemetry method. The main drawback termed in wireline logging method is sticking of pipe which is overcome in LWF logging while fishing method._When we have a problem with sticking of pipe implementation of LWF allows retrieving the pipe by fishing operation along with logging operation. The logging operations are resumed at the time of fishing operations optimizes the rig time and cost. This project briefs about Logging While Drilling, logging while fishing in Tough logging conditions. The history of LWD and LWF along with its trend in India is discussed. Some logs interpreted help to get good in a site of the project. In a reservoir with a gas cap and bottom water drive, it is possible to select the perforation depth and the saturation. The Neutron porosity-density cross-over plot provides the oil-water and gas-oil contact. Coning and cusping are the common problems of any reservoir with gas and water boundaries. During the production, if observed the saturation can be determined by the correlation of neutron density log and resistivity logs. It is possible to select the shut-in time to decrease the saturation levels. 


\section{References}

[1] Cho, H. and Shah, S. N., 2000. "Optimization of well length for horizontal drilling." In J Can Pet Technol, PETSOC-02-05-03.2000.

[2] Bemani, A. S., Boukadi, F. H., and Wahaibi, Y., 2000. "Horizontal well length optimization for a South Oman field." Pet. Sci. Technol., vol. 18, pp. 121-140.

[3] labo, J., 1987. "A practical introduction to borehole geophysics an overview of wireline well logging principles for geophysicists." Society of Exploration Geophysicists, vol. 2, Available: https://library.seg.org/doi/abs/10.1190/1.9781560802587

[4] Mansour, H., Ahmad, M. M., Dhafr, N., and Ahmed, H., 2013. "Evaluation of operational performance of workover rigs activities in oilfields." Int. J. Product. Perform. Manag., vol. 62, pp. 204-218.

[5] Haris, A., 2012. "Workover and completion operations in East Java sour gas field, Indonesia." In Soc. Pet. Eng. - SPE/APPEA Int. Conf. Heal. Saf. Environ. Oil Gas Explor. Prod. 2012 Prot. People Environ. - Evol. Challenges. pp. 45-52.

[6] Quinn, T. H., Dwyer, J., Wolfe, C., Morris, S., and Coope, D., 2008. "Formation evaluation logging while drilling (LWD) in unconventional reservoirs for production optimization." In SPE Eastern regional section.SPE-119227.

[7] Kulananpakdee, K. "Through-drill pipe logging and formation sampling in deviated and risky wells | weatherford international." Available: https://www.weatherford.com/en/documents/papers/2018/throughdrill-pipe-logging-and-formation-sampling-in-deviated-and-risky-wells/

[8] Han, G. Z. and Ai, C., 2013. "Applications of mud pulse MWD/LWD system in bakken formation, North Dakota, USA." Appl. Mech. Mater., vol. 415, pp. 672-676.

[9] Liétard, O., Unwin, T., Guillot, D. J., and Hodder, M. H., 1999. "Fracture width logging while drilling and drilling mud/loss-circulation-material selection guidelines in naturally fractured reservoirs." SPE Drill. Complet, vol. 14, pp. 168-177. Available: https://doi.org/10.2118/57713-PA

[10] Hunter, J., Maranuk, C., and Rodriguez, A., 2014. "Unique application of em LWD casing antenna system to rocky mountain drilling." In Soc. Pet. Eng. - SPE West. North Am. Rocky Mt. Jt. Meet.

[11] Neto, A. O., Dutta, D., and Hassan, S., 2009. "Successful application of new LWD platform provides integrated real-time formation evaluation in the Mediterranean reservoirs." In Soc. Pet. Eng. - SPE/IATMI Asia Pacific Oil Gas Conf. Exhib. 2009, APOGCE 09. pp. 460-464.

[12] Mendoza, A., 2010. Quantitative formation evaluation in high angle and horizontal wells using LWD measurements: Field application of integrated log modeling workflows vol. 1. Soc. Pet. Eng. - SPE Russ. Oil Gas Tech. Conf. Exhib. 2010, RO G 10, pp. 255-269.

[13] Srinivasan, A., Frisby, R., Talbot, T., and Paraschiv, M., 2010. "New directional drilling with liner systems allows logging and directional control while getting casing across trouble zones." In Soc. Pet. Eng. - Int. Oil Gas Conf. Exhib. China 2010, IOGCEC. pp. 1860-1868.

[14] Elshahawi, H., Garcia, M. D., Garcia, J. P., and Li, C., 2020. "Real time monitoring and control of wireline logging operations." In SPWLA 61st Annual Logging Symposium. SPWLA-5070.

[15] Doventon, J. H. and Prensky, S., 1992. "Geological applications of wireline logs: A synopsis of developments and trends." Log Anal., vol. 33, pp. 286-303. 